\title{
Pseudocholinesterase activity in thyroid disease
}

\author{
J. C. THOMPSON AND MARY WHITTAKER \\ From the Group Laboratory, Lewisham Hospital, London, and \\ the Biochemistry Department, King's College, University of London
}

SYNOPSIS The present evidence indicates that serum pseudocholinesterase activity is increased to about $20 \%$ above the normal level in thyrotoxicosis and decreased by about $30 \%$ in myxoedema. Treatment restores the esterase level to the average mean activity of random normal as the patient becomes euthyroid.

There is no evidence in the present investigation that any of the pseudocholinesterase variants modify these conclusions.

Many pathological conditions have been shown to alter serum cholinesterase levels in man. A decrease in serum cholinesterase activity is associated with liver disease (McArdle, 1940) and organophosphorus poisoning (Barnes and Davies, 1951). Other pathological conditions in which a decrease in activity has been reported are malnutrition (Waterlow, 1950); severe anaemia (Scudamore, Vorhaus, and Kark, 1951); hyperpyrexia (Antopol, Tuchman, and Schifrin, 1937); infectious diseases (Hall and Lucas, 1937); cardiac failure, uraemia (McArdle, 1940); catatonia (Tod and Jones, 1937); and malignancy, particularly of the alimentary tract (Koster and Kisch, 1943). An increase in serum cholinesterase level has been reported in obesity (Berry, Cowin, and Davies, 1954); nodular goitre (Koster and Kisch, 1943); psoriasis (Helmeczy and Nagy, 1954); and essential hypertension (Reinfrank and Whetstone, 1958). A high esterase level was found by chance in a patient known to have a high basal metabolic rate and so it was decided to study esterase levels in thyrotoxicosis and myxoedema.

A series of 60 such cases was investigated and in some patients it has been possible to follow esterase levels during differing treatments. The esterase levels of many of the patients were determined after they had become euthyroid.

\section{METHODS}

Pseudocholinesterase activity using acetylcholine as substrate was determined micromanometrically (Callaway, Davies, and Rutland, 1951). The esterase activity using benzoylcholine as substrate was determined in $\mathrm{M} / 15$ phosphate buffer at $p \mathrm{H} 7.4$ at $26.5^{\circ} \mathrm{C}$. by the method of Kalow and Lindsay (1955).

Received for publication 21 April 1965.
Dibucaine numbers were determined by the method of Kalow and Genest (1957) and fluoride numbers by the method of Harris and Whittaker (1961). The percentage inhibition of benzoyl cholinesterase by dibucaine is termed the dibucaine number and the fluoride number is similarly defined. All the readings on the spectrophotometer were measured directly and not automatically recorded.

\section{PATIENTS STUDIED}

Samples of plasma were obtained from 60 patients of Dr. J. S. Staffurth of Lewisham Hospital. Fortyeight were diagnosed as having thyrotoxicosis and 12 as having myxoedema. In as many cases as possible the pseudocholinesterase levels were determined following treatment.

\section{RESULTS}

The average esterase levels for both substrates in patients with thyrotoxicosis and myxoedema are shown in Table I. In addition the esterase levels for

\section{T A B LE I}

MEAN SERUM CHOLINESTERASE ACTIVITIES OF THE USUAL PHENOTYPE

\begin{tabular}{|c|c|c|c|c|c|}
\hline \multirow{3}{*}{$\begin{array}{l}\text { Pathological } \\
\text { Condition }\end{array}$} & \multirow{3}{*}{$\begin{array}{l}\text { Number } \\
\text { Tested }\end{array}$} & \multicolumn{4}{|c|}{ Substrate } \\
\hline & & \multicolumn{2}{|c|}{ Acetylcholine } & \multicolumn{2}{|c|}{ Benzoylcholine } \\
\hline & & $\begin{array}{l}\text { Mean } \\
\text { Activity }\end{array}$ & S.D. & $\begin{array}{l}\text { Mean } \\
\text { Activity }\end{array}$ & S.D. \\
\hline $\begin{array}{l}\text { Hyperthyroid } \\
\text { Hyperthyroid now }\end{array}$ & 48 & 124 & 24 & 124 & 30 \\
\hline euthyroid & 32 & 98 & 22 & 100 & 30 \\
\hline Hypothyroid & 12 & 75 & 25 & 73 & 35 \\
\hline Random normals & 94 & 107 & 19 & & \\
\hline Random normals & 402 & & & 103 & 24 \\
\hline
\end{tabular}




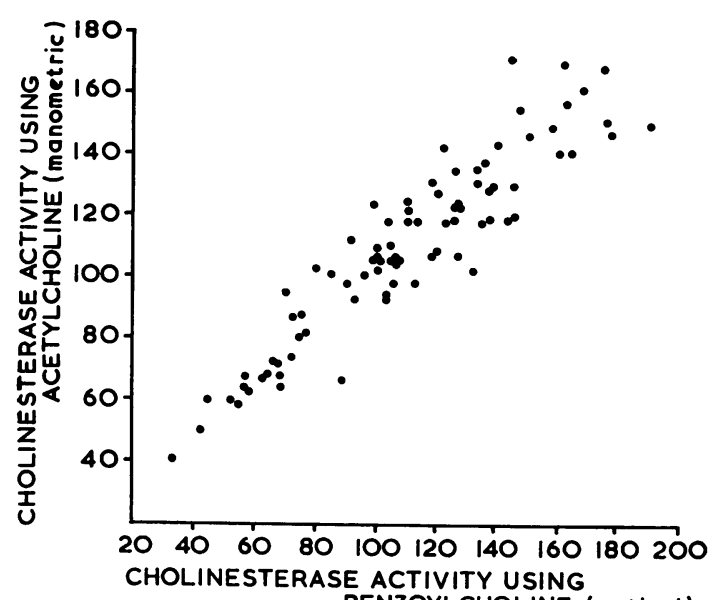

FIG. 1. Scatter diagram for the two metıods for estimating pseudocholinesterase activity.

patients who became euthyroid after treatment for hyperthyroidism are recorded.

Dibucaine numbers and fluoride numbers of all sera were measured in order to eliminate any of the known pseudocholinesterase variants. All the esterase levels quoted in Table I are of the usual phenotype (Kalow and Staron, 1957). A good correlation exists between the activities using acetylcholine and benzoylcholine as substrates (Fig. 1).

\section{DISCUSSION}

A mean increase of activity was observed in esterase levels of patients with thyrotoxicosis when compared with the esterase levels found in a random sample of the population (Table I). This increase in activity is of the magnitude of $20 \%$ and was found for both substrates.

One patient with thyrotoxicosis was found to be an heterozygote phenotype. The esterase levels using acetyl and benzoyl-choline were 107 and 118 units respectively. This phenotype has been shown to average 79 units (S.D. = 23) for 122 individuals using benzoylcholine as substrate (Whittaker, 1964) and 80 units (S.D. $=21$ ) for 37 individuals with acetylcholine as substrate. Neither the atypical nor the fluoride-resistant phenotypes were encountered during this survey.

As soon as the patients became euthyroid the esterase levels were measured by both methods. The results (Table 1) are in good agreement with the activities found in the random normals.

It is interesting to follow the level of esterase activity during the therapeutic treatment of thyrotoxicosis with ${ }^{131}$ I. Using acetylcholine as substrate the serum cholinesterase activity in one such subject was $168,140,120$, and 122 units when the patient $\underset{\vec{\rho}}{\vec{\rho}}$ had become clinically euthyroid. Fluctuations in pseudocholinesterase levels have also been observed with remission and recurrence of thyrotoxicosis. $\bar{s}$ One thyrotoxic patient had an initial activity of 143 units which after treatment fell to 98 when she was clinically euthyroid. A year later she was again o thyrotoxic with an esterase level of 136 units. $\overrightarrow{0}$ When she again became euthyroid the pseudocholinesterase activity was found to be 117 units. A similar variation occurred using benzoylcholine as substrate.

In the 12 patients with myxoedema the mean $\vec{\phi}$ activity for pseudocholinesterase level was about $30 \%$ lower than that found in random normals $\stackrel{\infty}{\vec{\prime}}$ using either substrate. It has not been possible to follow the treatment of these patients until they became euthyroid except in one case when the activity $\vec{z}$ rose from 93 units (acetylcholine) before treatment to 135 units at the time when the patient became euthyroid, illustrating that even when myxoedema is not associated with a subnormal esterase activity, a rise in activity does occur when the patient becomes euthyroid. $\vec{\bullet}$

Electrophoresis has revealed that 'normal' serum of cholinesterase can be classified into two variants, $\mathrm{C}_{5}+$ and $\mathrm{C}_{5}-$. The variant $\mathrm{C}_{5}+$ has been shown to have a mean activity of about $30 \%$ higher than those of the $\mathrm{C}_{5}$ - individuals, using benzoylcholine as substrate (Harris, Hopkinson, Robson, and Whittaker, 1963). One of the sera investigated in this instance was of the $\mathrm{C}_{5}+$ type, in a myxoedemic patient. In this case the esterase levels for both substrates were 105 units which is about $33 \%$ higher than the mean activity for the other myxoedemic patients. This patient has yet to become euthyroid.

\section{REFERENCES}

Antopol, W., Tuchman, L., and Schifrin, A. (1937). Proc. Soc. exp. Biol., (N.Y.), 36, 46.

Barnes, J. M., and Davies, D. R. (1951). Brit. med. J., 2, 816.

Berry, W. T. C., Cowin, P. J., and Davies, D. R. (1954). Brit. J. Nutr., $8,79$.

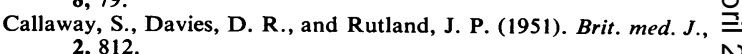

Hall, G. E., and Lucas, C. C. (1937). J. Pharmacol. exp. Ther., 59, 34. Љ Harris, H., Hopkinson, D. A., Robson, E. B., and Whittaker, M. N (1963). Ann. hum. Genet., 26, 359.

- and Whittaker, M. (1961). Nature (Lond.), 191, 496.

Helmeczy, L., and Nagy, E. (1954). Acta med. Acad. Sci. hung., 5, 109. Kalow, W., and Genest, K. (1957). Canad. J. Biochem., 35, 339.

— and Lindsay, H. A. (1955). Ibid., 33, 568.

- and Staron, N. (1957). Ibid., 35, 1305.

Koster, H., and Kisch, B. (1943). Exp. Med. Surg., 1, 71.

McArdle, B. (1940). Quart. J. Med., 9, 107.

Reinfrank, R., and Whetstone, H. J. (1958). Hartford Hosp. Bull, 31, 32.

Scudamore, H. H., Vorhaus, L. J., II, and Kark, R. M. (1951). Blood, $6,1260$.

Tod, H., and Jones, M. S. (1937). Quart. J. Med., 6, 1.

Waterlow, J., (1950). Lancet, 1, 908.

Whittaker, M. (1964). Acta genet. (Basel), 14, 281. 